\title{
A[ए]
}

School of Economics

Working Paper Series

\section{Evaluating the Impact of 20 Hours Free Early Childhood Education on Mothers' Labour Force Participation and Earnings}

Isabelle Bouchard Lydia Cheung Gail Pacheco

2018/05 


\title{
Evaluating the Impact of 20 Hours Free Early Childhood Education on Mothers' Labour Force Participation and Earnings
}

\author{
Isabelle Bouchard * Lydia Cheung ${ }^{\dagger} \quad$ Gail Pacheco ${ }^{\ddagger}$
}

\begin{abstract}
New Zealand introduced a substantial childcare subsidy just over a decade ago, providing 20 hours free early childhood education (ECE) to all three- and four-year-olds. We evaluate the impact of this policy shift on mothers' labour market participation and earnings. Using a difference-in-differences strategy and population-wide administrative panel data, we follow mothers' quarterly earnings from pre-pregnancy to six years post-childbirth. The estimated impact of the ECE reform varies depending on the number of children eligible. For mothers with one child, there is some evidence of a drop in labour market participation and earnings, which potentially indicates this group is using the savings in ECE expenditure, a gain in real income, to consume more non-work time. For mothers with two eligible children, there is an increase in labour market participation, potentially because these households find it more worthwhile to increase ECE consumption and return to work when there are two children who benefit from the policy.
\end{abstract}

JEL classification: C21; H40; J13; J22

Keywords: early childhood education; difference-in-differences; mothers' earnings; intertemporal substitution; administrative data

* HEC Montréal. isabelle.4.bouchard@gmail.com

†Auckland University of Technology. lydia.p.cheung@aut.ac.nz. Corresponding author.

₹ New Zealand Work Research Institute, Auckland University of Technology. gail.pacheco@aut.ac.nz. 


\section{Disclaimer}

The results in this paper are not official statistics. They have been created for research purposes from the Integrated Data Infrastructure (IDI), managed by Statistics New Zealand.

The opinions, findings, recommendations, and conclusions expressed in this paper are those of the authors, not Statistics NZ.

Access to the anonymized data used in this study was provided by Statistics NZ under the security and confidentiality provisions of the Statistics Act 1975. Only people authorized by the Statistics Act 1975 are allowed to see data about a particular person, household, business, or organisation, and the results in this paper have been confidentialized to protect these groups from identification and to keep their data safe.

Careful consideration has been given to the privacy, security, and confidentiality issues associated with using administrative and survey data in the IDI. Further detail can be found in the Privacy impact assessment for the Integrated Data Infrastructure available from www.stats. govt.nz.

The results are based in part on tax data supplied by Inland Revenue to Statistics NZ under the Tax Administration Act 1994. This tax data must be used only for statistical purposes, and no individual information may be published or disclosed in any other form, or provided to Inland Revenue for administrative or regulatory purposes.

Any person who has had access to the unit record data has certified that they have been shown, have read, and have understood section 81 of the Tax Administration Act 1994, which relates to secrecy. Any discussion of data limitations or weaknesses is in the context of using the IDI for statistical purposes, and is not related to the data's ability to support Inland Revenue's core operational requirements. 


\section{Introduction}

Public spending on childcare policies is of great interest to policy makers on two fronts. First, childcare subsidies increase access to early childhood education (ECE) opportunities for a wider range of children, especially for those from poor socio-economic households. It is expected that ECE attendance will give children a greater probability of success in school, which will likely result in positive long-term outcomes. Second, it promotes improved female labour market outcomes. Childcare costs are one of the potential obstacles for women with young children to re-enter the labour market after childbirth. Its impact on mothers' engagement with the labour market is the focus of this study. More specifically, we contribute to the empirical evidence on the causal impact of childcare policies (namely, ECE subsidies) on mothers' labour force participation and earnings for the case study of New Zealand (NZ).

$\mathrm{NZ}$ is similar to a number of other developed countries whereby mothers still experience a labour market wage disadvantage. Interestingly, women across the working age population (15to 64-year-olds) have a relatively high labour force participation rate, eighth highest in the OECD; but when the focus is narrowed to the dominant child-bearing age (25- to 34-year-olds), NZ's ranking falls to twenty-sixth. ${ }^{1}$ Furthermore, close to one third of working women in NZ are in part-time employment (Pacheco, Li, \& Cochrane, 2018). Internationally, one of the most cited reasons for women's limited labour market participation is the cost of childcare (Baker, Gruber, \& Milligan, 2008; Baum, 2002; Hegewisch \& Gornick, 2011; Lefebvre \& Merrigan, 2008).

In July 2007, the NZ Labour-led government introduced a policy of 20 hours per week free ECE for all three- and four-year-olds in services led by a qualified and registered early childhood teacher. When announced in 2004, the policy was unanticipated by the early childhood community. It brought about a major increase in public funding for ECE (Bushouse, 2008). Within six months of implementation, 76 percent of ECE providers had joined the 20-hoursfree ECE program (May, 2008) and the number of children enrolled in ECE increased from 165,254 in 2006 to 176,993 in 2008 (Ministry of Education, 2013). ${ }^{2}$ Furthermore, public spending on ECE rose exponentially from $\$ 574$ million in 2006 to $\$ 837$ million in 2008, and up to $\$ 1.157$ billion by 2010 .

\footnotetext{
${ }^{1}$ This is based on 2006 data from the OECD: https://data.oecd.org/emp/labour-force-participation-rate.htm 2 Of course, we cannot attribute this increase solely to the ECE subsidy as there are numerous other factors that could jointly affect ECE participation, such as population growth dynamics, for instance.
} 
To assess the impact of the ECE reform, we employ newly linked administrative data sources from the Integrated Data Infrastructure (IDI). This permits a population-wide perspective, as well as the ability to link information across sources based on a unique identifier assigned to each individual. The IDI allows identification of all NZ births via Department of Internal Affairs (DIA) records. Through linking Inland Revenue tax data, we are able to follow patterns in mothers' labour market participation and earnings from pre-pregnancy to six years postchildbirth.

Our empirical approach exploits the temporal variation in childcare coverage induced by the difference in birth years. As the program is implemented simultaneously across NZ, we do not have a concurrent comparison group, like untreated states or regions. Instead, we use a child's birth date to define the treatment and control groups of mothers. The control group is a cohort of mothers who gave birth between July 2000 and June 2002 and hence whose child(ren) are not eligible for ECE subsidy; the treatment group is a cohort of mothers who gave birth between July 2004 and June 2006 and hence whose child(ren) are eligible for the subsidy. These mothers are compared in two sets of analysis: the first concerns eligible and non-eligible mothers with one child, the second compares eligible and non-eligible mothers with two children. For contemporaneous comparison, we then add a second control group: a matched sample of women with no children (henceforth 'non-mothers'). Some of these non-mothers would have been eligible for the policy if they had a child during our study period. This group provides a control for time-specific effects, such as the macroeconomic environment that may affect employment. Moreover, we compare the labour force participation and earnings for each treated mother, in each quarter after childbirth, to a matched control mother and a matched non-mother. We therefore have four groups for our difference-in-differences (DiD) analysis: eligible mothers, eligible non-mothers, non-eligible mothers and non-eligible non-mothers.

Our study makes several contributions to the extant literature. We add to the scant body of causal evidence that focuses on childcare policies and women's labour market outcomes. Our study is also the first to look at the impact of the 20 hours ECE reform in NZ. Considering the magnitude of this reform, it presents a unique opportunity to understand the related outcomes. Finally, with the use of population-wide administrative data, we can evaluate the impact of the ECE reform on both the population as a whole and for disaggregate groups of interest, i.e. mothers with one eligible child versus two eligible children.

The outline of the paper is as follows. Section 2 documents the empirical evidence from the key literature on childcare subsidies and the impact on mothers' labour market outcomes. 
Section 3 outlines the ECE reform implemented in 2007. Section 4 describes the administrative data sources and methodology we use. Section 5 presents our results. Section 6 concludes.

\section{Literature Review}

In this study we focus on the impact of childcare policies on mothers' labour market participation and earnings. The trade-off between costs associated with childcare and the wages earned at work is an important element of the mothers' decision to re-enter the workforce after childbirth. Much of the early literature on childcare policies has focused exclusively on the individual response to cost schedules in a non-experimental setting (Anderson, Binder, \& Krause, 2002; Anderson, Binder, \& Krause, 2003; Blau \& Currie, 2006; Lundin, Mörk, \& Öckert, 2008; Wrohlich, 2004; Anderson, Binder, \& Krause, 2003; Blau \& Currie, 2006; Lundin, Mörk, \& Öckert, 2008; Wrohlich, 2004). The price elasticity estimates uncovered in this space are wide ranging, extending from -0.02 (Wrohlich, 2004) to -0.92 (Kimmel, 1998).

More recently, there is a growing body of empirical studies that apply quasi-experimental identification strategies created by exogenous policy changes. These studies span different countries, mostly in Europe plus some in North America. Here, we separate these papers into two groups: those that found significant effects on maternal labour force participation and/or labour supply, and those that did not. We briefly summarise the policy analysed by each study and their results, starting with those that found positive and significant effects.

Firstly, Carta and Rizzica (2018) analysed a 2003 reform in Italy that gave early access to subsidised childcare for two-year-olds. Exploiting the discontinuities in eligibility rules and staggered implementation, the authors found the policy increased mothers' labour force participation and decreased the reservation wage of the unemployed. Secondly, Haeck, Lefebvre and Merrigan (2015) studied the Early Childhood Education and Care program in Québec, Canada. This program was phased in between 1997 and 2000 to increase mothers' labour force participation and enhance child development. Publicly regulated childcare facilities were required to offer spaces at $\$ 5$.0o per day per child. The authors used a DiD approach to compare children in Québec to the rest of Canada. They found a positive, large and significant effect on the labour force participation of mothers with children aged one to four.

Thirdly, Bauernschuster and Schlotter (2015) looked at the introduction of a legal claim to a place in kindergarten in 1996 for three- and four-year-olds in Germany. This claim was contingent on day-of-birth cut-off dates. Using both instrumental variable and DiD estimations, the authors found that kindergarten eligibility increased the probability of employment for mothers by 6 percent. The authors estimated a local average treatment effect which identified a 3.7 percent increase in mothers' employment attributable to the 10 percent increase in childcare attendance. Fourthly, Hardoy and Schøne (2015) evaluated the impact of cheaper childcare in 
Norway after the implementation of the Child Care Centre Agreement in 2003. In a triple difference framework, they compared the labour supply of eligible mothers, before and after childbirth, with that of non-eligible mothers and mothers with older children who were also not eligible. They found that the childcare reform increased the employment rate of women with children by approximately 5 percent. Lastly, Sall (2014) analysed the introduction of prekindergarten funding in the U.S. during the 1980 s and 1990s. The author took advantage of the staggered timing in funding and found that mothers with a four-year-old, with or without any other younger children, were significantly more likely to be in the labour force once prekindergarten becomes available.

Several other studies found no effect on maternal labour force participation or labour supply from various childcare policy changes. Firstly, in the Netherlands, Bettendorf, Jongen and Muller (2015) looked at the introduction of the Law on Childcare in 2015. This policy brought about a substantial increase in childcare subsidies, benefiting parents aged 20 to 50 years old with a youngest child up to 12 years of age. Using a DiD strategy with parents whose youngest child was between 12 and 17 years old as the control group, they found the policy increased mothers' employment by just over 2 percent; maternal hours worked increase by 1.1 hours per week. Furthermore, these rather small effects were likely confounded by the implementation of targeted earned income tax credits for parents over the same time period. Secondly, Drange and Telle (2015) analysed an intervention in Oslo where children aged four and five were eligible for twenty hours of free childcare per week. While enrollment of children from immigrant families increased by 15 percent, comparison across districts with and without this intervention showed no effect on parental labour force participation or education.

Thirdly, Havnes and Mogstad (2011) studied a staged expansion of subsidised childcare in Norway in 1975. All children aged three to six years old were eligible for the subsidy regardless of parents' employment or marital status. The authors focused on married mothers' employment and full-time equivalent status. Using a DiD that exploits temporal and spatial variation in childcare coverage, they found little casual effect. The authors argued that the new childcare subsidy was crowding out informal childcare arrangements. 3 Fourthly, Goux and Maurin (2010) focused on the universal rules of French public schools where children start pre-elementary school in the year they turn two or three years old. Preschool eligibility for the September school year thus depends on a child's date of birth. This creates a sharp discontinuity in enrollment percentage between children born in late December and early January. Using a regression discontinuity design, Goux and Maurin (2010) showed that early preschool eligibility has a significant effect on the labour force participation of single mothers, but no effect on two-parent families. Fitzpatrick (2010) produced a similar study on two prekindergarten programs in

3 The latter was widely used prior to the new subsidy because subsidised childcare in Norway was severely rationed. 
Georgia and Oklahoma for children aged four by the September school year. While state-wide preschool enrollment increased by 14 percent, estimation results from a regression discontinuity framework showed no significant effect on maternal labour supply, either in terms of the discrete status of working or the hours worked per week. Lastly, Lundin, Mörk and Öckert (2008) evaluated the 2002 introduction of a cap to childcare prices in Sweden. The extent of the price reduction depended on the family type and region of residence. Using a DiD matching regressions approach, the authors found no significant effect on mothers' employment probabilities or labour supply as a share of full-time employment.

Given the mixed findings in the literature on childcare subsidies and maternal labour market outcomes, our study provides a timely addition to the knowledge in this space. Furthermore, the extent of NZ's childcare reform provides enhanced motivation for our empirical analysis.

\section{Policy Background}

NZ's ECE sector has undergone a significant transformation over the last century, including both policy shifts and changes in the social, economic and cultural landscape. In the first half of the twentieth century, women were encouraged to assume their responsibilities as mothers "at home" (May, 2002). This perspective was reinforced by social policies and public perceptions. During the 1960s and 1970s the perceived role of women slowly began to change as more women entered the workforce. In 1986 there was a major overhaul of the childcare sector as the government integrated all ECE services ${ }^{4}$ under the Ministry of Education (Meade \& Podmore, 2002). This step provided the necessary regulatory framework for the ECE sector. In 1988 the entire education system was reviewed and the 'Before Five' report was launched. Based on the recommendations within this report, the government introduced bulk funding for ECE services of $\$ 2.25$ per hour for up to 30 hours per week for children over two years old.

The ECE reform at the center of this study was announced in 2004 by the Minister of Finance in his budget speech to parliament. The new program was a shift from a per-hour subsidy to a 20-hours-free approach and was to be implemented in 2007 for all three- and four-year-olds in teacher-led services across the country. This marked a major increase in public funding for ECE and was therefore deemed a substantial policy shift, particularly towards increasing ECE accessibility for all families. When implemented in July 2007, the policy covered up to 6 hours

\footnotetext{
4 In general, ECE services cater for children from birth to school entry age, which is on or near their fifth birthday (Meade \& Podmore, 2002). Children are eligible to start at school on the day they turn five and must start before they turn six. There is no public provision of ECE services in NZ, rather it is organised by private or community-based providers, either teacher-led or parent-led.
} 
free ECE per day, for up to 20 hours free per week (May, 2002).

Unfortunately, we cannot ascertain the direct impact on ECE uptake for eligible children as ECE consumption data prior to 2008 is not available in the IDI framework. We therefore rely on aggregate information from the Annual ECE Census Summary Report from the Ministry of Education in $2014^{5}$ to illustrate ECE consumption patterns around the relevant time frame. The report provides trends from 2005 to 2014 on a binary indicator of ECE enrolment and a measurement of intensity with the average number of hours of ECE attendance per week. For example, the report shows that among three-year-olds in 2006, almost 90 percent were enrolled in ECE for an average of approximately 15 hours per week. While this indicates high usage of ECE in an age group targeted by the ECE reform, the summary report also indicates sharp increases in ECE consumption (for both the binary and intensity indicators) around 2007 and 2008 for three- and four-year-olds. Furthermore, to illustrate the subsidy impact across the ECE sector, it is worth noting that within six months of policy implementation 76 percent of ECE providers had chosen to join the program (May, 2002).

In terms of the monthly cost of ECE, the average revenue from one hour of ECE (in 2011 dollars) is $\$ 9.55$, weighted across different service types. ${ }^{6}$ Using the general consumer price index (CPI), this corresponds to about $\$ 8.00$ in the mid-200os. Thus, at the time of policy implementation, if a child consumed 20 hours of ECE per week for the thirteen weeks in a quarter, the parents' quarterly expenditure would have been approximately $\$ 2,080$ without the government subsidy.

Another mid-200os policy worth highlighting in parenthood setting is the government provision of paid parental leave (PPL). In the period relevant to our data, mothers were eligible for 12 weeks of PPL starting in July 2002 with 12 months of possible unpaid leave, potentially shared between parents. We take care to distinguish between earnings (paid by employers) and PPL (paid by the government) and exclude the latter in our analysis. NZ was one of the last OECD countries to introduce national legislation for PPL, together with Australia (Ravenswood \& Kennedy, 2012). The first relevant legislation was the Maternity Leave and Employment Protection Act in 1980, which introduced maternity leave and job protection for eligible women. While PPL increased to 18 weeks in April 2016 and again to 22 weeks in July 2018, for the time period of our study the policy was consistent at 12 weeks paid leave.

\footnotetext{
5 See http://www.educationcounts.govt.nz/publications/series/annual-early-childhood-education census, figures 1.9 and 1.23 .

${ }^{6}$ See 2011 survey at https://www.educationcounts.govt.nz/publications/ECE/income-expenditure-and-fees-of-eceproviders-in-new-zealand.
} 
In terms of the expected impact of the ECE policy reform on mothers' labour market outcomes, classic microeconomic theory suggests the effect could be either positive or negative. For all eligible mothers who would have purchased ECE services regardless of a government subsidy, the policy reduces their out-of-pocket expenses. This represents an increase in real income, if we hold the prices of other consumable items fixed. If we model mothers' decisions on the number of working hours using indifference curves between consumption and leisure (i.e. non-work hours, which can be dedicated to child rearing at home), the ECE policy shifts the optimal choice to one at a higher budget line and indifference curve. The number of hours worked at this new optimum could be more than, equal to, or less than the old optimum, depending on the shape of the indifference curves. There can be both an income effect (mothers' out-of-pocket ECE expenses decreases) and a substitution effect (the effective wage increases, thus the opportunity cost of leisure increases). If mothers work less in response to an increase in real income, and if the substitution effect outweighs the income effect, leisure is a normal good; if mothers respond with increased work, leisure is an inferior good. The latter case is more likely if mothers are consuming more hours of ECE services as a result of the policy than they would have otherwise, and thus are able to use these additional child-free hours for work. Nonetheless, this classic static theory does not tell us about the timing of the mothers' responses.

The aim of our empirical study is to discover whether non-work hours for new mothers are a normal or inferior good. We also examine the impact in a dynamic context to understand whether there are changes to mothers' labour market participation and earnings between the child's birth date and the age of six; a period that covers years when the child is both eligible and non-eligible for the ECE subsidy.

\section{Data and Method}

Statistics New Zealand's Integrated Data Infrastructure (IDI) is a large research database containing micro-data on individuals and households, encompassing the NZ population. The IDI includes administrative data from a range of government and non-government agencies, and official surveys. All data is confidentialised and individual-level information can be linked across datasets and time via an individual's unique identifier.

Within the IDI we can identify mothers who are eligible for the ECE policy (treatment group) and mothers that are not (control group), based on the timing of their childbirths, and trace any changes in their labour market outcomes. As the ECE policy is available to all mothers nationwide, there is no control group of mothers that can be simultaneously compared against 
the treated mothers. We therefore use matched non-mothers as an additional control group for contemporaneous comparisons with mothers in the treatment and control groups. This creates four groups of women, each with a complete time series of earnings, that we use in our DiD analysis; namely, eligible mothers, eligible non-mothers7 ${ }^{7}$, non-eligible mothers and non-eligible non-mothers.

Our starting point in the IDI is the birth registration dataset from the DIA, which contains all births and adoptions. For births within the period of interest, we retrieved the list of mothers' identifiers. We also collected relevant demographic information about these mothers, such as their age, educational attainment and ethnicity from the Census 2013 data. We then merged their monthly earnings from the Inland Revenue (IR) dataset. We sourced wage and salary income from the Employer Monthly Schedule (EMS) but excluded PPL and various sources of governmental non-employment income, such as unemployment benefits, pension, welfare and student allowances. Employment earnings from different employers were aggregated to a single value for each individual-month observation. We focused on wages and salaries as they are the most common source of income and likely most impacted by childbirth (unlike capital income, for example). We further aggregated the earnings data from monthly to quarterly periods. One shortcoming of this administrative data is the lack of information on the number of hours worked: we cannot distinguish between changes in hourly wages from changes in the number of hours worked.

We constructed our study population as follows. We started with the entire population of mothers who gave birth between July 2004 and June 2006 for the treatment group, and those between July 2000 and June 2002 for the control group. For these two groups of mothers, we identified all the children they have given birth to, not limited to those in our treatment and control windows, using the DIA data. From this subset of 198,ooo mothers, we eliminated all mothers who gave birth to a stillborn, as well as those with missing demographic variables. We also restricted our analysis to mothers with one or two children, which represent the majority of mothers in NZ. In addition, we excluded mothers who gave birth outside the age range of 20 to 55 years old to avoid extreme observations. All aggregated quarterly earnings were normalised to constant June 2006 dollars using the quarterly seasonally adjusted CPI series provided by Statistics New Zealand. We also eliminated mothers with extreme monthly income observations exceeding $\$ 15,000$.

\footnotetext{
7 A more verbose description for the group of 'eligible non-mothers' would be: non-mothers who would otherwise be eligible if they had a child during our definition period.
} 


\subsection{Matching treatment and control mothers}

For the ease of all future references, we name the relevant groups of mothers as follows. Groups $1 \mathrm{~N}$ and $1 \mathrm{E}$ are mothers of one child where ' $\mathrm{N}$ ' denotes 'non-eligible' and ' $\mathrm{E}$ ' denotes 'eligible'. Mothers of group $1 \mathrm{~N}$ gave birth between July 2000 and June 2002. This cohort of children were all older than four years of age when the policy started in July 2007, making them not eligible for the ECE policy and thus serve as the control group. Mothers of group $1 \mathrm{E}$ gave birth between July 2004 and June 2006. This cohort of children all reached the age of three in July 2007 or later, thus making up the treatment group as they were all eligible for the ECE policy.

Groups $2 \mathrm{~N}$ and $2 \mathrm{E}$ are mothers of two children that are either both non-eligible or both eligible for the ECE subsidy, respectively. Group $2 \mathrm{~N}$ denotes mothers whose second (younger) child was born between July 2000 and June 2002, so that none of the two children were eligible for the policy. Group 2E denotes mothers whose first (older) child was born between July 2004 and June 2006, so that both children were eligible.

In summary, group $1 \mathrm{E}$ is the treatment group while group $1 \mathrm{~N}$ is the control group when the treatment is having one child who is eligible for free ECE. Similarly, group 2E is the treatment group and group $2 \mathrm{~N}$ is the control group when the treatment is having two children who are both eligible for free ECE. Because the treatments are different across these two sets of comparison groups, we do not directly compare mothers with a different number of children. In addition, we have ensured that both treatment groups were well informed of the new policy. ${ }^{8}$

For mothers with one child, there is a natural reference point in time: the quarter in which they gave birth. We label that quarter $q=0$ and reference all earnings observations relative to that event time. ${ }^{9}$ For these mothers, we compare earnings in the period $4 \leq q \leq 23$, when their child is between one and five years old. For mothers with two children, we label the first childbirth $q_{1}=0$ and the second childbirth $q_{2}=0$. The time gap between the two childbirths can span a wide range; each childbirth brings forth a loss in earnings and a subsequent recovery. We concentrate on the mothers with the most frequent time gaps: between six and eleven quarters, inclusive. This group constitutes two-thirds of all mothers with two children. We analyse their earnings series after their second childbirth and reference all earnings observations against $q_{2}=$ o.

\footnotetext{
8 When we search for "20 hours ECE” in the Newztext Database, from 1 Jan 2004 to 31 Dec 2007, it yields 319716 search results, across newspapers, magazines, and newswires. The number of search results distribute evenly across the years.

9 This is instead of referencing against a point in calendar time.
} 
To enhance the comparability of all four groups of mothers in our DiD analysis, we match each mother in the treatment groups $(1 \mathrm{E}$ and $2 \mathrm{E})$ to a mother in a respective control group ( $1 \mathrm{~N}$ and $2 \mathrm{~N}$ ). For each treatment mother, we first identified the list of control mothers with identical birth year, birth quarter, ethnicity, educational attainment level and age (measured in quarters) at first (and second) childbirth(s). We then extracted pre-motherhood earnings in the period -5 $\leq q \leq-2$ for mothers with one child and $-5 \leq q_{1} \leq-2$ for mothers with two children. ${ }^{10}$ We computed the total squared difference in earnings for each potential pair. Each treatment mother is then matched (with replacement) to the control mother with the smallest squared difference in earnings among the list. This process forms the four study groups of mothers ${ }_{1} \mathrm{E}$, $1 \mathrm{~N}, 2 \mathrm{E}, 2 \mathrm{~N}$ ) that we use in all subsequent analysis.

\section{Table 1: Summary statistics of treatment mothers}

\begin{tabular}{lll}
\hline & $1 \mathrm{E}$ & $2 \mathrm{E}$ \\
\hline Age: & 32.529 & 30.924 \\
At first childbirth & $(5.685)$ & $(4.342)$ \\
At second childbirth & - & $\begin{array}{l}33.007 \\
(4.340)\end{array}$ \\
\hline Highest educational qualification: & - & \\
No school & 0.085 & 0.048 \\
School qualification & 0.627 & 0.564 \\
Bachelors & 0.252 & 0.350 \\
Post-graduate & 0.037 & 0.038 \\
\hline Ethnicity: & 0.779 & 0.914 \\
NZ European & 0.049 & 0.024 \\
Asian & 0.044 & 0.013 \\
Maori & 0.128 & 0.049 \\
Pacific & 5916 & 8991 \\
\hline Unique individuals &
\end{tabular}

Notes: $\mathrm{N}=$ non-eligible; $\mathrm{E}=$ eligible. Means are provided for demographic variables and standard deviations are in parenthesis. Data source = IDI. Authors' compilation.

Table 1 presents demographic summary statistics for each treatment group of mothers in our study. We omit the control groups $(1 \mathrm{~N}, 2 \mathrm{~N})$ because they have identical demographic characteristics as the treatment groups to which each is matched. Table 1 shows that mothers in group $2 \mathrm{E}$ are younger than mothers in group $1 \mathrm{E}$ when they have their first child. On average, 2E mothers are more educated and have a higher proportion of NZ European. The reason for these demographic differences is multifaceted. Underlying population changes and selfselection (into motherhood and the number of children) are both at play, however each is a substantial topic on its own, both beyond the focus of this paper. Because we conduct separate analysis for groups $1 \mathrm{E}$ and $2 \mathrm{E}$, and since the matching procedure ensured each comparison

10 These earnings observations can be positive or zero: when the mother is either unemployed or out of the labour force. 
group has identical demographic characteristics to their respective treatment group, the demographic differences between $1 \mathrm{E}$ and $2 \mathrm{E}$ should not affect the validity of our results.

\subsection{Matching mothers to non-mothers}

Besides using non-eligible mothers as comparison groups, we also sourced women with no children as additional control groups. To locate these non-mothers in the IDI, we first used Census 2013 data to identify all women in NZ, then merged the DIA data which allowed us to exclude all women who had given birth or adopted at a given point in time. For non-mothers, we merged demographic information and IR data in the same manner described above. Finally, each mother in our treatment groups was matched to the most comparable non-mother; similar to the matching between treatment and control mothers. The only difference between these matching methods is that earnings are compared with reference to the women's age (measured in quarters) because non-mothers do not have natural time references $q=0$ or $q_{1}=0$. Squared differences are calculated from the differences in earnings observations when the mother and non-mother are of the same age.

Table 2: Mean participation and quarterly earnings (\$)

\begin{tabular}{lllll}
\hline & $\begin{array}{l}\text { Participation } \\
\text { period: }\end{array}$ & $\begin{array}{l}\text { Participation } \\
\text { Post }\end{array}$ & $\begin{array}{l}\text { Earnings } \\
\text { Pre }\end{array}$ & $\begin{array}{l}\text { Earnings } \\
\text { Post }\end{array}$ \\
\hline 1N mothers & 0.900 & 0.725 & 7382.026 & 5387.019 \\
1N non-mothers & 0.880 & 0.832 & 7307.055 & 8205.027 \\
1E mothers & 0.890 & 0.706 & 7973.013 & 5793.998 \\
1E non-mothers & 0.886 & 0.834 & 7902.626 & 8943.395 \\
2N mothers & 0.943 & 0.581 & 9537.902 & 4142.898 \\
2N non-mothers & 0.938 & 0.855 & 9373.292 & 10299.170 \\
2E mothers & 0.891 & 0.576 & 10102.015 & 4996.692 \\
2E non-mothers & 0.893 & 0.824 & 9834.492 & 11034.047 \\
\hline
\end{tabular}

Notes: The pre-period refers to $-5 \leq q \leq-2$, where $q=0$ denotes the calendar quarter of (first) childbirth. The post-period refers to $4 \leq q_{2} \leq 23$, where $q_{2}=0$ denotes the calendar quarter of the (second) childbirth. All earnings are adjusted by CPI to constant June 2006 dollars. $\mathrm{N}=$ non-eligible; $\mathrm{E}=$ eligible. Data source = IDI. Authors' compilation.

Table 2 shows the mean quarterly labour market participation and earnings by groups of mothers and matched non-mothers. The mean earnings summary includes instances of zero monthly earnings: we cannot distinguish whether these instances are due to unpaid leave, unemployment or women exiting the labour force. For mothers with one child, the pre-period refers to quarters $-5 \leq q \leq-2$ and the post-period refers to $4 \leq q \leq 23$. For mothers with two children, the pre-period refers to $-5 \leq q_{1} \leq-2$ and the post-period refers to $4 \leq q_{2} \leq 23$.

Table 2 shows that mothers' and matched non-mothers' mean labour force participation and earnings are extremely similar in the pre-periods. This confirms that our matching criteria successfully generated a comparable baseline for assessing the effect of motherhood on 
earnings. This similarity disappears after childbirth(s). For all groups of mothers, both the participation rate and average earnings drop sharply after childbirth(s). These changes are particularly severe for mothers with two children. Over the same period, all non-mother groups experience a slight decrease in labour market participation and an increase in average earnings. We attribute these to natural life-cycle decisions and career progression.

Next, we graph the time series of mean quarterly labour market participation and earnings of mother groups $1 \mathrm{~N}$ and $1 \mathrm{E}$ and their matched non-mothers (Figure 1). These graphs elaborate on the patterns evident in the summary statistics in Table 2. All groups of non-mothers experience a steady and mild decline in labour market participation rates, and an equally steady and mild increase in average quarterly earnings, throughout the entire study period.

Indeed, the participation and earnings patterns of non-mothers are very similar across all graphs in Figure 1, regardless of whether they are matched to mothers in the treatment or control group, with one or two children. This provides reassurance that non-mothers are a neutral and suitable group for contemporaneous counterfactual comparison.

Mothers' labour market time series are strikingly different from those of non-mothers. Mothers' participation and earnings start to drop about two quarters before childbirth, ${ }^{11}$ reaching a minimum in the quarter following childbirth, before starting to recover. For mothers with one child, quarterly participation drops from 0.9 to 0.4 around childbirth (Panel A), and earnings fall from $\$ 8,000$ to about $\$ 2,000$ (Panel C). For mothers with two children, the decline in labour market participation and earnings appear slightly less severe (Panel B and Panel D respectively); however, these drops are in fact similar to those of mothers with one child, and would appear so if the graphs were aligned at $q_{1}=o$ (first childbirth) instead of $q_{2}=0$ (second childbirth).

Figure 1 suggests recovery is most rapid in the first year after each childbirth. For all mother groups, labour force participation recovers to about 0.65 and earnings recover to $\$ 5,000$. For mothers with one child, both the participation rate and earnings increase steadily after one-year post-childbirth. Neither of these labour market variables recover to pre-motherhood levels in our study period, up to when the (only) child is five years old. The labour force participation rate almost catches up with that of the matched non-mothers (which steadily declines in the same period), but earnings never do.

For mothers with two children, both participation and earnings fall further when they give birth to their second child: participation falls to about 0.3 (Panel B) and earnings fall to below

\footnotetext{
${ }^{11}$ From our data exploration, we believe this is a general observation, and not solely an artefact of our choice on the matching window.
} 
$\$ 2,000$ (Panel D). The recovery pattern after the second childbirth is similar to that of the first childbirth: it is most rapid in the first year, then becomes steady but mild afterwards. There are signs of convergence in participation rate between mothers with two children and matched nonmothers, but this appears to come later than mothers with one child, and not within the time frame of our analysis (five years after the birth of the second child). In terms of earnings after the two childbirths, we see a persistent gap between mothers and matched non-mothers, larger than that between mothers of one child and matched non-mothers.

Figure 1: Labour market participation and earnings

Panel A.

Participation: Mothers of one child

Quarterly participation rate

mothers of one child

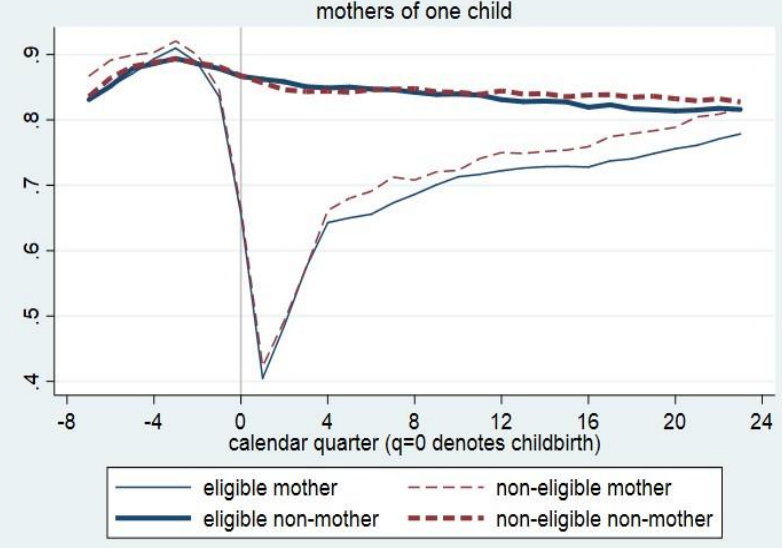

Panel B.

Participation: Mothers of two children

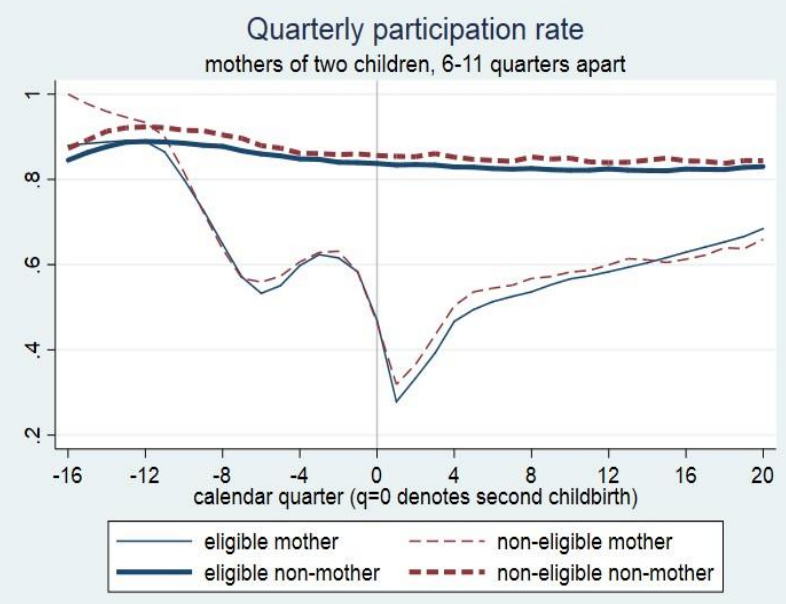


Panel C.

Earnings: Mothers of one child

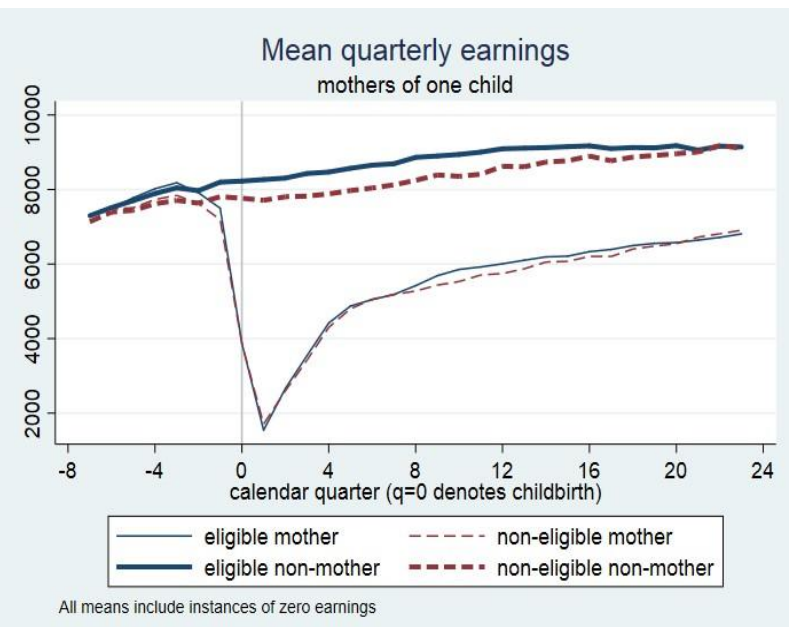

Panel D.

Earnings: Mothers of two children

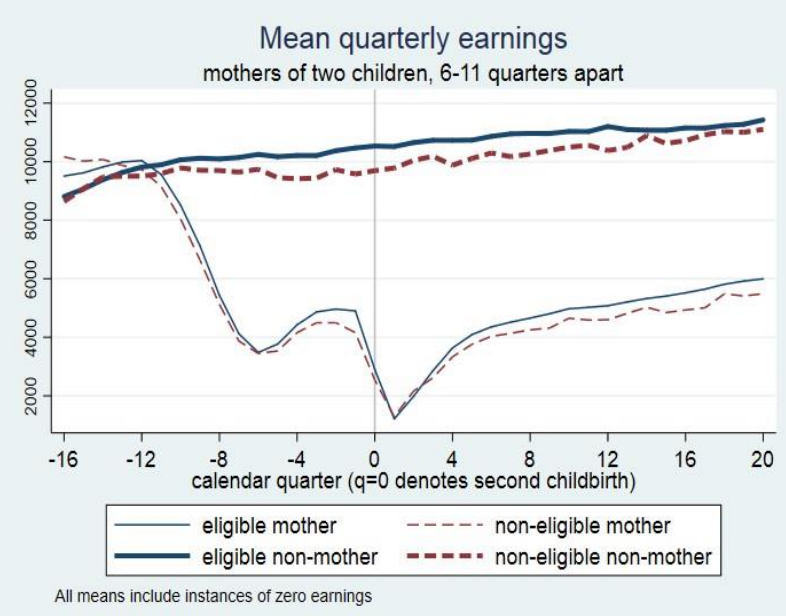

Data source = IDI. Authors' compilation.

\subsection{Method}

We perform DiD regression analysis on the effect of the ECE policy on quarterly labour force participation and earnings. We implement the following regression:

$$
Y_{i t}=\beta_{0}+\beta_{1} \text { Eligible }_{i}+\beta_{2} \text { Mother }_{i}+\beta_{3} \text { Eligible }_{i} * \text { Mother }_{i}+X_{i t}^{\prime} \delta+\tau_{t}+\varepsilon_{i t}
$$

where Eligible $_{i}$ is an indicator variable equal to 1 for all observations where individual $i$ belongs to the treatment group; Mother $_{i}$ is an indicator variable equal to 1 for all observations where individual $i$ is a mother; $X_{i t}$ is a vector of control variables; and $\tau_{t}$ are a set of time fixed effects. The parameter of interest $\left(\beta_{3}\right)$ is the coefficient of the interaction term Eligible $_{i} *$ Mother $_{i}$, providing the average treatment effect of the ECE policy.

We conduct two separate sets of analysis for mothers of one child and for mothers of two children, since the 'treatment' and the benefit from the policy differs by the number of eligible children. We do not combine these subjects to maintain the ceteris paribus condition in each treatment effect analysis. We use all observations in quarters $4 \leq q \leq 23$ for mothers of one child (and matched non-mothers), and $4 \leq q_{2} \leq 23$ for mothers of two children (and matched nonmothers). In other words, we use all observations starting one year after the mother's last (or only) childbirth, ending with the quarter before the same child turns six years old. We use the contemporaneous time period for all matched non-mothers. We therefore assume, through our matching on demographic characteristics and pre-motherhood earnings, that for each treated 
mother, the outcomes of matched mothers in the control group serves as the counterfactual had the treated mother not received an ECE subsidy. By the same logic, the matched non-mother serves as a contemporaneous counterfactual had the treated mother not had children.

A single difference between a mother (treatment or control) and her matched non-mother gives the 'motherhood wage penalty'. ${ }^{12}$ Thus, our DiD analysis can be interpreted as the difference in the 'motherhood wage penalty' brought by the ECE subsidy. To capture any changes in the DiD estimator $\left(\beta_{3}\right)$ over time, we estimate the ECE effect for each quarter by interacting the DiD estimator with a quarter indicator. In each set of analysis, we investigate the effects on two dependent variables: discrete labour market participation and continuous earnings. All regressions on participation are probit regressions, while all regressions using earnings are Heckman regressions (Heckman, 1974). We use each woman's demographic characteristics, her total income not sourced from wages and salaries or PPL and the contemporaneous national unemployment rate to control for selection into the labour market. This set of selection variables is similar to those used by Nicodemo (2007).

We note that while some other studies ${ }^{13}$ are able to use supply-side variation to help identify the policy effect in the absence of a natural experiment, unfortunately this is not feasible in our case. The IDI does not contain any information on ECE providers. Unlike primary and secondary schools, there are no public providers of ECE in NZ. The annual ECE Census, conducted by the Ministry of Education (not StatsNZ), dates back to 2005 at the earliest. This is not early enough for us to establish an empirical relationship between ECE supply and consumption for our control groups. The publicly available Annual ECE Census Summary Reports do not provide detailed local-level data on the number of providers or their capacity. National or highly-aggregated regional data are not appropriate, since parents access ECE locally.

We select the timeframes and definitions for the treatment and control groups above in an attempt to capture the policy effect sufficiently, while minimizing the exposure to other influences if possible. Other definitions are certainly possible; for example, some studies use mothers with multiple children (as opposed to non-mothers) as a control group. We acknowledge that we cannot rule out all other possible explanations to the effects we find. For example, we have no data on individual employers' parental leave or childcare benefits. It is also possible that our DiD framework does not capture all potential dimensions of differences, such as, for example, when macroeconomic fluctuations affect mothers and non-mothers differently.

\footnotetext{
${ }^{12}$ Some sources may define a 'motherhood wage penalty' differently. For example, the difference in income between a comparable man and woman who are both parents.

13 Such as Tanaka (2014) and Finkelstein (2007).
} 


\section{Results}

Table 3 provides our overall regression results. The four columns show the regressions on labour force participation and earnings for our two sets of subjects. Group 1 includes mothers in groups $1 \mathrm{E}$ and $1 \mathrm{~N}$, and their matched non-mothers. Group 2 includes mothers in groups $2 \mathrm{E}$ and $2 \mathrm{~N}$, and their matched non-mothers. All our regressions include quarter-specific intercepts and the indicator variables Mother and Eligible, together with their interaction which provides the DiD estimator. However, to conserve space we display only the latter. ${ }^{14}$

Table 3: DiD regressions

\begin{tabular}{|c|c|c|c|c|}
\hline \multirow{2}{*}{$\begin{array}{l}\text { Dependent variable: } \\
\text { Subjects: }\end{array}$} & \multicolumn{2}{|c|}{ Participation } & \multicolumn{2}{|c|}{ Earnings } \\
\hline & group 1 & group 2 & group 1 & group 2 \\
\hline \multicolumn{5}{|l|}{ DiD estimator } \\
\hline$q=4$ & $-0.072 * *$ & 0.003 & -281.368 & -233.796 \\
\hline$q=5$ & $-0.116 * * *$ & -0.029 & -141.244 & 76.929 \\
\hline$q=6$ & $-0.102 * * *$ & -0.001 & $-314.939 *$ & 98.580 \\
\hline$q=7$ & $-0.109 * * *$ & 0.006 & $-353.388 * *$ & 35.080 \\
\hline$q=8$ & -0.038 & 0.031 & $-326.250 *$ & 32.054 \\
\hline$q=9$ & -0.041 & $0.051^{*}$ & -2.849 & 101.128 \\
\hline$q=10$ & -0.018 & $0.074 * *$ & -86.594 & -228.530 \\
\hline$q=11$ & $-0.069^{*}$ & 0.044 & -161.500 & 87.646 \\
\hline$q=12$ & -0.030 & 0.017 & -101.602 & -301.852 \\
\hline$q=13$ & -0.022 & 0.021 & -201.418 & -138.520 \\
\hline$q=14$ & -0.026 & $0.079 * * *$ & -206.854 & -81.573 \\
\hline$q=15$ & -0.047 & $0.149 * * *$ & -135.194 & -96.181 \\
\hline$q=16$ & -0.023 & $0.120^{* * *}$ & -109.221 & -107.786 \\
\hline$q=17$ & -0.056 & $0.126 * * *$ & -69.356 & 209.805 \\
\hline$q=18$ & -0.055 & $0.093^{* * *}$ & -56.996 & -82.800 \\
\hline$q=19$ & -0.033 & $0.143^{* * *}$ & -140.482 & -82.052 \\
\hline$q=20$ & -0.037 & $0.124^{* * *}$ & -152.852 & -137.045 \\
\hline$q=21$ & $-0.094^{* *}$ & $0.057^{*}$ & 89.944 & 218.422 \\
\hline$q=22$ & $-0.076^{* *}$ & 0.023 & 66.649 & -68.384 \\
\hline$q=23$ & $-0.094^{* *}$ & 0.044 & 111.467 & $569.818^{* *}$ \\
\hline log-likelihood & -242028.867 & -397805.019 & -12012.260 & -14568.466 \\
\hline$N$ & 473040 & 718569 & 90201 & 718569 \\
\hline
\end{tabular}

Notes: Group 1 subjects include $1 \mathrm{~N}$ mothers, $1 \mathrm{E}$ mothers, and their matched nonmothers. Group 2 subjects include $2 \mathrm{~N}$ mothers, $2 \mathrm{E}$ mothers, and their matched non-mothers. We use all observations in quarters $4 \leq q \leq 23$ for mothers of one child (and matching non-mothers), and $4 \leq q_{2} \leq 23$ for mothers of two children (and matching non-mothers). Probit regressions are used where the dependent variable is participation. Heckman regressions are used where the dependent variable is earnings. ${ }^{*} p<0.1,{ }^{* *} p<0.05,{ }^{* * *} p<0.01$

Table 3 shows that, for mothers with one child, the effect of the ECE policy is negative and significant on labour market participation when the child is one year old and again when the same child is five years old. The coefficient translates to approximately four percentage points

14 The indicator variables on their own have signs that we expected based on results in Figure 1. The Mother indicator is always negative and significant. The Eligible indicator is mostly negative and significant in participation regressions, and positive and significant in earnings regressions. 
in terms of the participation rate. The magnitude of this effect is in line with the studies cited earlier. Otherwise, all other DiD estimates are not statistically significant.

For mothers with two children, the participation effect of the policy is positive and significant when the second child is between three and four years old-i.e. when the child is eligible for 20 hours of free ECE. This translates to about two percentage points of the participation rate. This estimate is evidence that the ECE policy had a positive impact on some mothers' labour market outcomes. The remaining earnings DiD estimates do not differ significantly between the subject groups and are small in magnitude relative to the pre-motherhood quarterly earnings shown in Table 2.

\subsection{Caveats}

Here we name three caveats for interpreting the findings in our study. Firstly, there is a lack of information on the supply of ECE spaces at the time of the policy implementation. While we know the majority of ECE providers did participate in the program, we cannot gauge from the administrative data as to whether all parental demand for ECE services was satisfied. One possible reason we do not find an expansion of maternal earnings might be that mothers failed to find ECE spaces for their children, because provision is not guaranteed by the policy.

Secondly, there were occasional ad hoc reports of ECE providers using various loopholes to extract additional payment from parents. Examples include imposing a minimum number of 21 enrolment hours (i.e. one hour more than the policy's coverage) and charging a high marginal price for the last hour or creating additional 'optional' charges such as donations.

Thirdly, one may reasonably suspect that mothers' fertility choices may be influenced by the policy. The impact of this endogeneity would bias our results towards zero. However, if we consider the timing of the policy announcement, the length of a full-term pregnancy and the windows we used to define our mother groups, mothers in most of our study groups were unlikely to have had enough time to conceive and give birth to a child in response to the policy announcement. The only exception is group $2 \mathrm{E}$ : this group is most susceptible to be incentivised by the policy to have their second child. In the formation of the $2 \mathrm{E}$ group of mothers, we only constrained the timing of their first child (between July 2004 and June 2006), not their second child. Thus, they would have had time to conceive and carry their second pregnancy to full term if it were purely incentivised by the policy. In other words, in the counterfactual scenario with no ECE subsidy, some of these mothers might be in group $1 \mathrm{E}$ instead of group $2 \mathrm{E}$. 


\section{Discussion and conclusion}

In this paper we analysed the effect of NZ's 20-hours-free ECE policy on mothers' labour force participation and earnings. This 2007 policy fully subsidised ECE for three- and four-year-olds for up to 20 hours per week. We used administrative data with earnings observations from prepregnancy to six years post-childbirth. We employed a difference-in-differences (DiD) methodology to compare eligible mothers' quarterly earnings post-childbirth against those of non-eligible mothers and comparable contemporaneous women who were not mothers.

We found that for mothers with one child, there is some evidence of a drop in labour market participation and earnings before the child becomes eligible for free ECE at age three. What mechanisms may be at play here? We speculate that the policy may have reduced some mothers' anxiety in re-entering the labour force or fully restoring their earnings in the early years of motherhood, in anticipation of the reduced expenses on ECE when their child reaches three years old. This explanation is supported by the fact that the policy was announced by the Labour Party three years prior to implementation. Thus, while our study timeframe and design should not have permitted an impact on fertility decisions, it is not implausible that mothers of eligible children in our study, born between July 2004 and June 2006, were aware of the policy around the time of their childbirths and planned their return to work accordingly. These mothers likely value time off work more than earnings, more so in the first few years of motherhood than the later years when their child reaches the eligible age. Thus, non-work hours are a normal good for these mothers, not an inferior good. These mothers are therefore smoothing their savings on childcare expenses across time by forgoing earnings earlier and taking advantage of the ECE policy later.

For mothers with two eligible children, there is an increase in labour force participation when the child is eligible for the policy benefit. The likely reason behind this finding is that these households find it worthwhile to increase ECE consumption and return to work when they have two children benefitting from the policy.

These findings further add to the body of knowledge on the causal impact of childcare subsidies and reforms, with a particular focus on the impact on mothers' engagement with the labour market. Future research could add additional perspectives, such as the impact on child wellbeing and development (including early school outcomes), as well as parent wellbeing. 


\section{References}

Anderson, D. J., M. Binder, and K. Krause (2002): "The motherhood wage penalty: Which mothers pay it and why?," American Economic Review, 92(2), 354-358.

(2003): "The motherhood wage penalty revisited: Experience, heterogeneity, work effort, and work-schedule flexibility," Industrial and Labor Relations Review, 56(2), 273-294.

Baker, M., J. Gruber, and K. Milligan (2008): "Universal child care, maternal labor supply, and family well-being," Journal of political Economy, 116(4), 709-745.

Bauernschuster, S., and M. Schlotter (2015): "Public child care and mothers' labor supplyEvidence from two quasi-experiments," Journal of Public Economics, 123, 1-16.

Baum, C. L. (2002): "A dynamic analysis of the effect of child care costs on the work decisions of low-income mothers with infants," Demography, 39(1), 139-164.

Bettendorf, L. J., E. L. Jongen, and P. Muller (2015): "Childcare subsidies and labour supply-Evidence from a large Dutch reform," Labour Economics, 36, 112123.

Blau, D., and J. Currie (2006): "Pre-school, day care, and after-school care: who's minding the kids?," Handbook of the Economics of Education, 2, 1163-1278.

Bushouse, B. K. (2008): "Early childhood education policy in Aotearoa/New Zealand: The creation of the 20 hours free programme," Fulbright New Zealand.

Carta, F., and L. Rizzica (2018): "Early kindergarten, maternal labor supply and children's outcomes: Evidence from Italy,” Journal of Public Economics, 158, 79-102.

Drange, N., and K. Telle (2015): "Promoting integration of immigrants: Effects of free child care on child enrollment and parental employment," Labour Economics, 34, 26-38.

Finkelstein, A. (2007): “The aggregate effects of health insurance: Evidence from the introduction of Medicare," Quarterly Journal of Economics, 112(1), 1-37.

Fitzpatrick, M. D. (2010): "Preschoolers enrolled and mothers at work? The effects of universal prekindergarten," Journal of Labor Economics, 28(1), 51-85.

Goux, D., and E. Maurin (2010): "Public school availability for two-year olds and mothers' labour supply,” Labour Economics, 17(6), 951-962.

Haeck, C., P. Lefebvre, and P. Merrigan (2015): "Canadian evidence on ten years of universal preschool policies: The good and the bad," Labour Economics, 36, 137-157.

Hardoy, I., and P. Schøne (2015): "Enticing even higher female labor supply: The impact of cheaper day care," Review of Economics of the Household, 13(4), 815-836.

Havnes, T., and M. Mogstad (2011): "Money for nothing? Universal child care and maternal employment," Journal of Public Economics, 95(11-12), 1455-1465.

Heckman, J. J. (1974): “Sample selection bias as a specification error,” Econometrica, 42, 679-94.

Hegewisch, A., and J. C. Gornick (2011): "The impact of work-family policies on women's employment: a review of research from OECD countries," Community, Work \& 
Family, 14(2), 119-138.

Kimmel, J. (1998): "Child care costs as a barrier to employment for single and married mothers," Review of Economics and Statistics, 80(2), 287-299.

Lefebvre, P., and P. Merrigan (2008): "Child-care policy and the labor supply of mothers with young children: A natural experiment from Canada," Journal of Labor Economics, 26(3), 519-548.

Lundin, D., E. Mörk, and B. Öckert (2008): "How far can reduced childcare prices push female labour supply?,” Labour Economics, 15(4), 647-659.

May, H. (2002): "Early Childhood Care and Education in Aotearoa-New Zealand: An overview of history, policy and curriculum," McGill Journal of Education, June, 1-15.

May, H. (2008): "Towards the right of New Zealand children for free early childhood education," International Journal of Child Care and Education Policy, 2(1), 77-91.

Meade, A., and V. N. Podmore (2002): "Early Childhood Education Policy Co-ordination under the Auspices of the Department/Ministry of Education: A Case Study of New Zealand. Early Childhood and Family Policy Series," UNESCO Early Childhood and Family Policy Series, 1, 1-34.

Nicodemo, C. (2007): "Participation and wage equations for married women in European countries," Working Paper, University of Tor Vergata, Rome.

Pacheco, G., C. Li, and B. Cochrane (2018): "Empirical evidence of the gender pay gap in New Zealand,” New Zealand Journal of Employment Relations, forthcoming.

Ravenswood, K., and A.-M. Kennedy (2012): "From unpaid maternity leave to paid parental leave in New Zealand: Changing approaches in legislation," Labour History, (102), 197-214.

Sall, S. P. (2014): "Maternal Labor Supply and the Availability of Public Pre-K: Evidence from the Introduction of Prekindergarten into American Public Schools," Economic Inquiry, 52(1), 17-34.

Tanaka, S. (2014): "Does abolishing user fees lead to improved health status? Evidence from post-apartheid South Africa," American Economic Journal: Economic Policy, 6(3), 282-312.

Wrohlich, K. (2004): "Child care costs and mothers' labor supply: an empirical analysis for Germany,” Discussion paper, DIW Discussion Papers. 